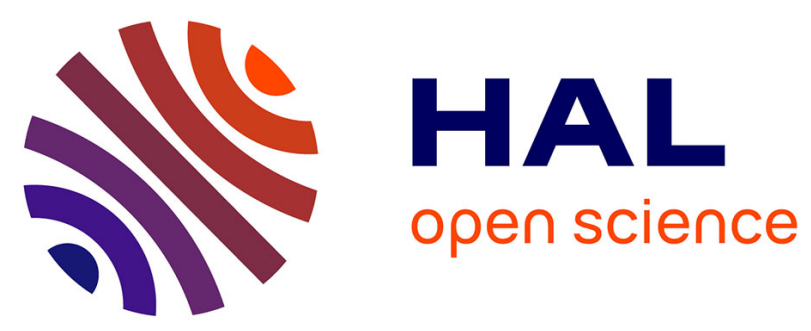

\title{
Velocity measurement of thermocapilary flows around a single vapor bubble of FC-72
}

Victor Carvalho, Magali Barthes, Valérie Lepiller, Yannick Bailly

\section{To cite this version:}

Victor Carvalho, Magali Barthes, Valérie Lepiller, Yannick Bailly. Velocity measurement of thermocapilary flows around a single vapor bubble of FC-72. AIAA Fluid Dyanmics Conference, Jun 2013,

San Diego, Ca, United States. hal-03223526

\section{HAL Id: hal-03223526 \\ https://hal.science/hal-03223526}

Submitted on 11 May 2021

HAL is a multi-disciplinary open access archive for the deposit and dissemination of scientific research documents, whether they are published or not. The documents may come from teaching and research institutions in France or abroad, or from public or private research centers.
L'archive ouverte pluridisciplinaire HAL, est destinée au dépôt et à la diffusion de documents scientifiques de niveau recherche, publiés ou non, émanant des établissements d'enseignement et de recherche français ou étrangers, des laboratoires publics ou privés. 


\title{
Velocity measurement of thermocapillary flows around a single vapor bubble of FC-72
}

\author{
Victor Carvalho ${ }^{1}$, Magali Barthès ${ }^{2}$, Valérie Lepiller $^{3}$ and Yannick Bailly ${ }^{4}$ \\ FEMTO-ST Institute, CNRS UMR 6174, 2 avenue Jean Moulin 90000 Belfort, FRANCE
}

\begin{abstract}
The importance of studying thermal phenomena that occurred near the vapor bubbles during boiling is crucial, like for instance in the field of Aerospatiale. Under specific conditions, convective motions, known as the Marangoni convection, can be observed at the liquid vapor interface. In order to study this convective effect, while avoiding effects due to bubbles coalescence, we focused on the case of a single vapor bubble growing underneath a heating element in a non-degassed subcooled liquid (FC-72). Experiments were carried out under normal conditions of gravity and pressure, and for various levels of liquid subcooling and wall heat flux. To characterize the Marangoni convection around a single vapor bubble in the presence of a temperature gradient, we used two optical metrology methods: Shadowgraphy and Particle Tracking Velocimetry (PTV). Threshold from stationary to oscillatory mode was investigated and found to be influenced by both wall heat flux and level of subcooling. Velocity vector fields in the vertical axis of the bubble were obtained for various thermal parameters, and maximum velocities in the convective rolls determined.
\end{abstract}

\section{Nomenclature}

$\sigma \quad=$ Surface tension

$T \quad=$ Temperature

$c \quad=$ Concentration

$E \quad=$ Electrical Potential

$P T V \quad=$ Particle Tracking Velocimetry

$\mathrm{Pc} \quad=$ Heating power

\section{Introduction}

$\mathrm{B}$ OILING phenomenon is of a high interest because of its cooling performances. More precisely, the nucleate pool boiling regime is very efficient since enabling high heat transfer for small increase in the wall superheat ${ }^{1}$. Moreover, when focusing on a single bubble, it was shown that flow could occur in the vicinity of the liquid-vapor interface. It was found that this flow around an interface causes a significant enhancement of heat transfer due to the convection in the vicinity of the surface. This convection, known as the Marangoni convection, is induced by a surface tension gradient along a liquid-gas interface ${ }^{2}$. The surface tension $\sigma$ is a function of the temperature $\mathrm{T}$, the concentration c, and the electrical potential E.

$$
\frac{\partial \sigma}{\partial x}=\frac{\partial \sigma}{\partial T} \frac{\partial T}{\partial x}+\frac{\partial \sigma}{\partial c} \frac{\partial c}{\partial x}+\frac{\partial \sigma}{\partial E} \frac{\partial E}{\partial x}
$$

If there is a gradient of one of these three quantities, there is a gradient of surface tension which behaves like a stress applied to the fluid near this interface. Thus the fluid moves in the direction of the increase of the surface tension. The Marangoni convection may also be called thermocapillary convection if the surface tension depends only on the temperature. For most liquids, the surface tension decreases when the temperature increases. Therefore,

\footnotetext{
${ }^{1}$ PhD Student, FEMTO-ST ENERGIE, victor.carvalho@ femto-st.fr.

${ }^{2}$ Associate professor, FEMTO-ST ENERGIE, magali.barthes@univ-fcomte.fr

${ }^{3}$ Associate professor, FEMTO-ST ENERGIE, valerie.lepiller@univ-fcomte.fr

${ }^{4}$ Full professor, FEMTO-ST ENERGIE, yannick.bailly@univ-fcomte.fr

1

American Institute of Aeronautics and Astronautics
} 
driven by Marangoni effect, the liquid moves from the hot area to the cold one, unlike the natural convection ${ }^{3,4}$. The origin of Marangoni convection (and more precisely the role of non condensable gases dissolved in the liquid) is very controversial $^{5,6,7}$. In this work we did not interested in the origin of the Marangoni convection, and we worked with a non degassed liquid.

Depending on different operating conditions, such as the size of the bubble, the level of subcooling or heat flux, Marangoni convection can be separated into, at least, two different regimes ${ }^{8,9}$ : the steady and the oscillatory ones. Reynard et al. ${ }^{8}$ experimentally studied the two regimes of Marangoni convection around a single air bubble injected into a silicone oil layer submitted to a vertical temperature gradient. From their results, it was shown that during the steady state, the Marangoni convection established as a torus in the horizontal plan. Whereas there was a rotary motion in the vertical plan, the torus was still in the horizontal plan. On the contrary, during the oscillatory regime, the torus was deformed and started a rotary motion in the horizontal plan around the bubble. Despite numerous works are reported in the literature concerning Marangoni convection around an air bubble ${ }^{3,4,8,10}$, fewer studies are carried out in the presence of a liquid-vapor interface ${ }^{11,12}$. More precisely, dynamics of the convective rolls are not well known and described.

In this study we focused on Marangoni effect around a single vapor bubble, created on a downward heating element. To highlight the different Marangoni regimes and study velocities of the rolls, a specific experimental setup was designed. It is presented in the next section. Then results obtained by shadowgraphy in different operative conditions are presented. In parallel to the shadowgraphy, we used another optical measurement method that allowed us to obtained velocity vector fields: PTV (Particle Tracking Velocimetry) ${ }^{13}$.

\section{Experiment setup and methods}

The experimental setup we designed to study Marangoni convection around a single vapor bubble is given on the Fig. 1. It is composed of the test cell which is linked to an expansion vessel to ensure the cell's pressure to stay at the atmospheric one. The cell is a cubic stainless steel one which has 4 sides equipped with glass windows for optical visualization. The two last sides are used to support elements: whereas the back of the cell maintained thermal sensors and liquid bulk's heaters, the top of the cell enables to carry the downward facing heating element. The later is localized in the middle of the test cell. The vapor bubble is created underneath the heating element, on an artificial nucleation site in the center of a copper disk (cf. Fig. 2).

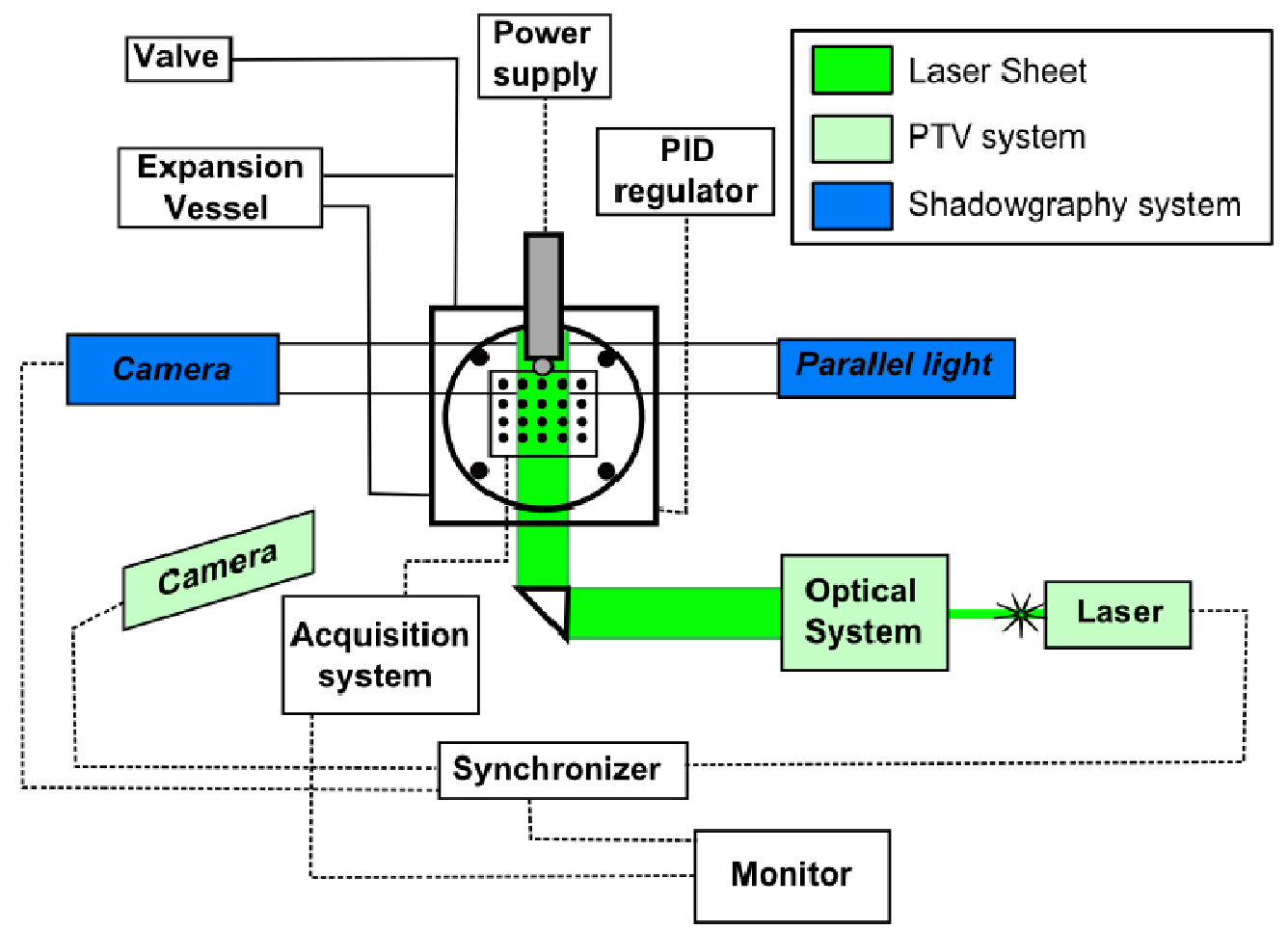

Figure 1. Experimental setup

American Institute of Aeronautics and Astronautics 


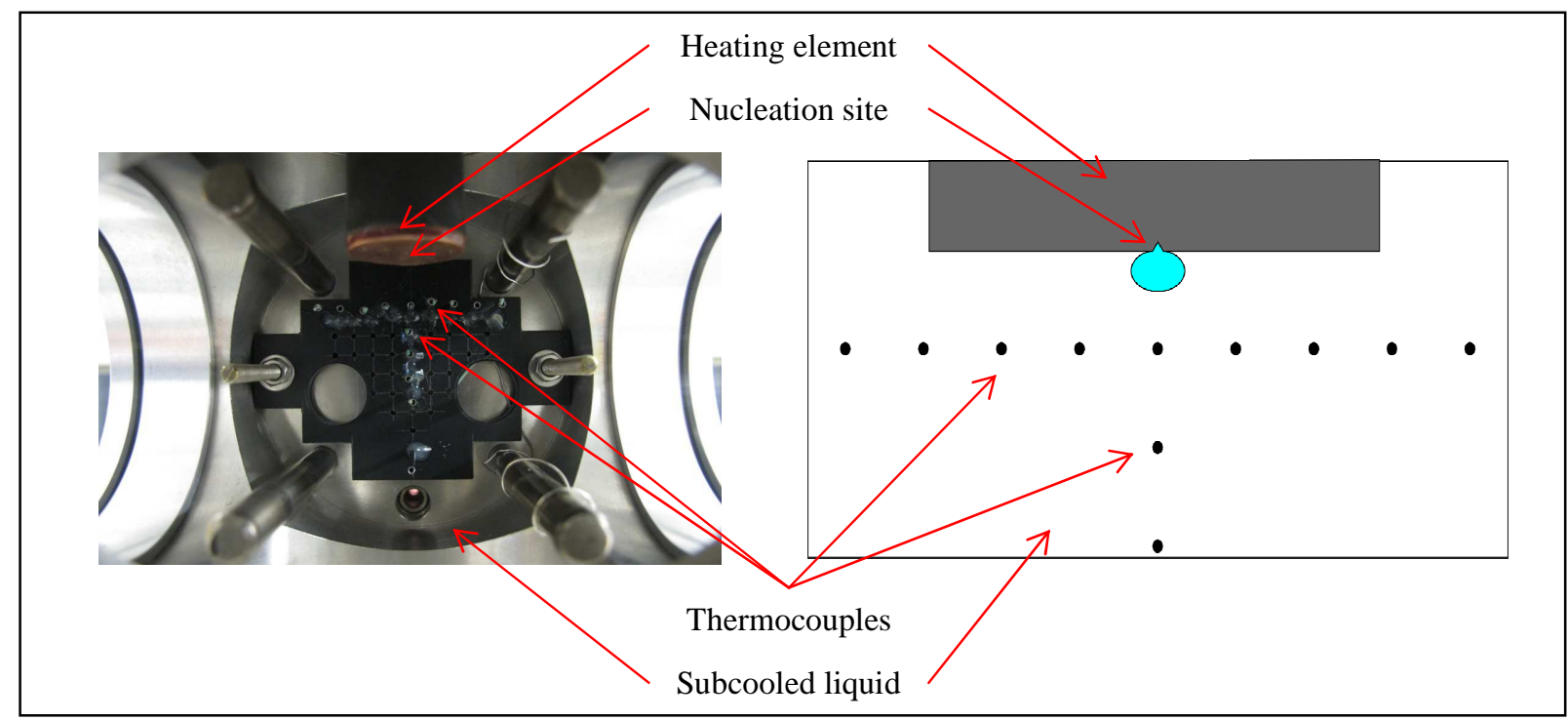

Figure 2. Downward facing heating element and nucleation site

Concerning the operation conditions, we worked with FC-72 (boiling temperature at our working pressure: $56.7^{\circ} \mathrm{C} \pm 0.1^{\circ} \mathrm{C}$ ). The liquid was non-degassed and subcooled (from 15.6 To $27.4^{\circ} \mathrm{C} \pm 0.5^{\circ} \mathrm{C}$ ). The wall heat flux on heating surface was set constant at 1.24 or $1.62 \mathrm{~W} \pm 0.19 \mathrm{~W}$.

Two optical methods were used simultaneously to study Marangoni effect. The first one was the shadowgraphy. Its principle is rather simple: to illuminate an object subjected to refractive index variation, and to watch the image obtained behind this object (its shadow). When there are temperature variations, the refractive index varies too. So, in our case, Shadowgraphy method enabled us to visualize convective motion in the liquid around the vapor bubble. The second optical method we used was the PTV (Particle Tracking Velocimetry), which has for principle to follow motion of seeding particles into the fluid: velocity vector fields of the flow are then obtained after a specific image processing. The test fluid was seeded with hollow glass beads coated with silver $(12 \mu \mathrm{m}$ in diameter $)$. Using optical components (spherical and cylindrical lenses), a Nd-Yag laser beam (532 nm) was spread into a sheet for illuminating a plan of the test cell. Particles located in this laser sheet were illuminated and consecutive images of the flow recorded by a camera (PIVCam 13-8, TSI) which observation direction was perpendicular to the laser sheet. A synchronizer was used to trigger laser pulses emission and images acquisition. In this study, the image processing was done using the commercial software Insight (TSI). For each particle, its displacement between two images was determined, and then the associated velocity vector calculated. A velocity vector field was then constructed.

\section{Results and discussions}

During the study, we obtained velocity vector fields around the vapor bubble using the PTV method. In parallel, using the shadowgraphy method allowed us to visualize the regime of Marangoni convection. As previously mentioned, we worked at constant wall heat flux equal to 1.24 or $1.62 \mathrm{~W} \pm 0.19 \mathrm{~W}$. The tested levels of subcooling were from 15.6 to $27.4{ }^{\circ} \mathrm{C} \pm 0.5{ }^{\circ} \mathrm{C}$.

The shadowgraphy method allowed us to observe the change between the stationary and the oscillatory Marangoni regime. In Fig. 3, we can see a series of shadowgraph of the vapor bubble during its growth. On the first pictures (A) there is a bright halo around the bubble that has no visible motion. This halo is due to the existence of convective roll near the liquid-vapor interface and corresponds to the stationary regime of Marangoni convection. Then this bright halo is axis symmetrically deformed, giving the impression of pulsations on the two sides of the bubble: it corresponds to the beginning of the oscillatory regime. Finally on the last images (C) the bright halo is completely distorted (and no more axis symmetric) before the departure of the bubble.

From our Shadowgraphy experiments, we reported the diameter (called "critical diameter") corresponding to the change between the stationary to the oscillatory mode. Results obtained for two heating power and various levels of subcooling enabled us to obtain the separating curve from stationary to oscillatory mode (cf. Fig. 4). We found that the critical bubble diameter increased when the levels of subcooling decreased, or when the heating power decreased. This can be explained by the fact that when decreasing the levels of subcooling or the heating power, the 
temperature gradient decreased too. As a result, the surface tension also decreased. It seemed thus logical to find higher critical diameter for smaller heating power, at a same level of subcooling.

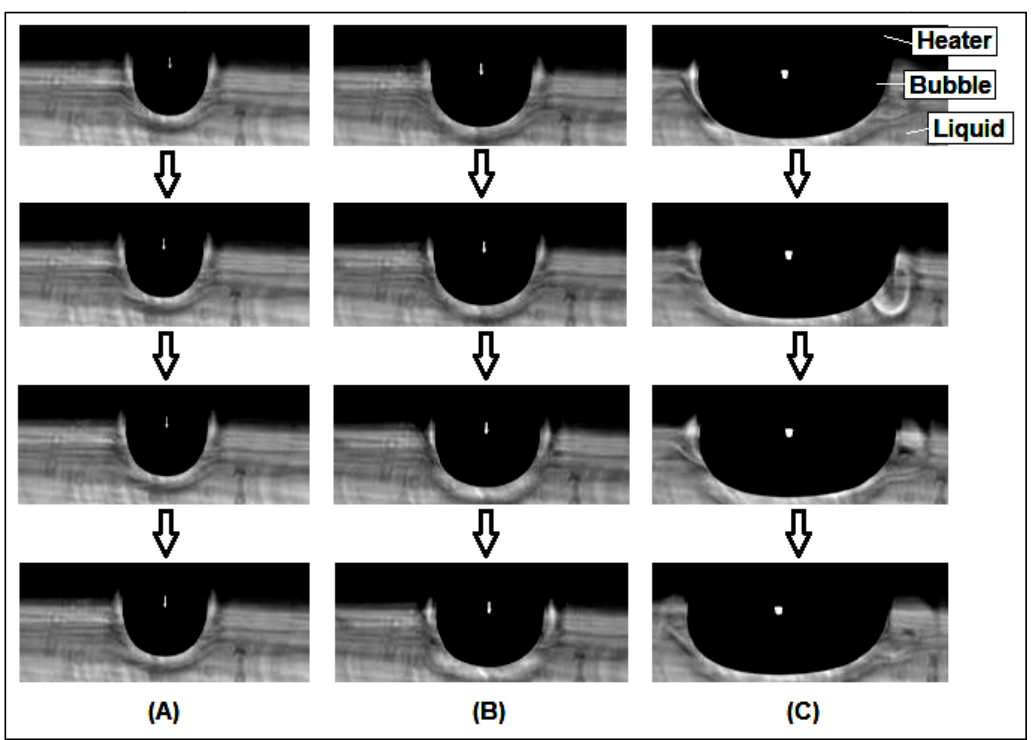

Figure 3. Pictures of the different Marangoni modes around a single vapor bubble growing on a downward facing heating element. Observed using shadowgraphy method.

These results are also consistent with the one obtained by Reynard et al. ${ }^{8}$ The first part of their study was carried out around an air bubble injected in a liquid layer (silicone oil or FC-72) submitted to a vertical temperature gradient. They found that the critical bubble diameter also increased when decreasing the temperature gradient. Moreover, they also carried out experiments with a single vapor bubble and we found a similar separating curve to the one they obtained.

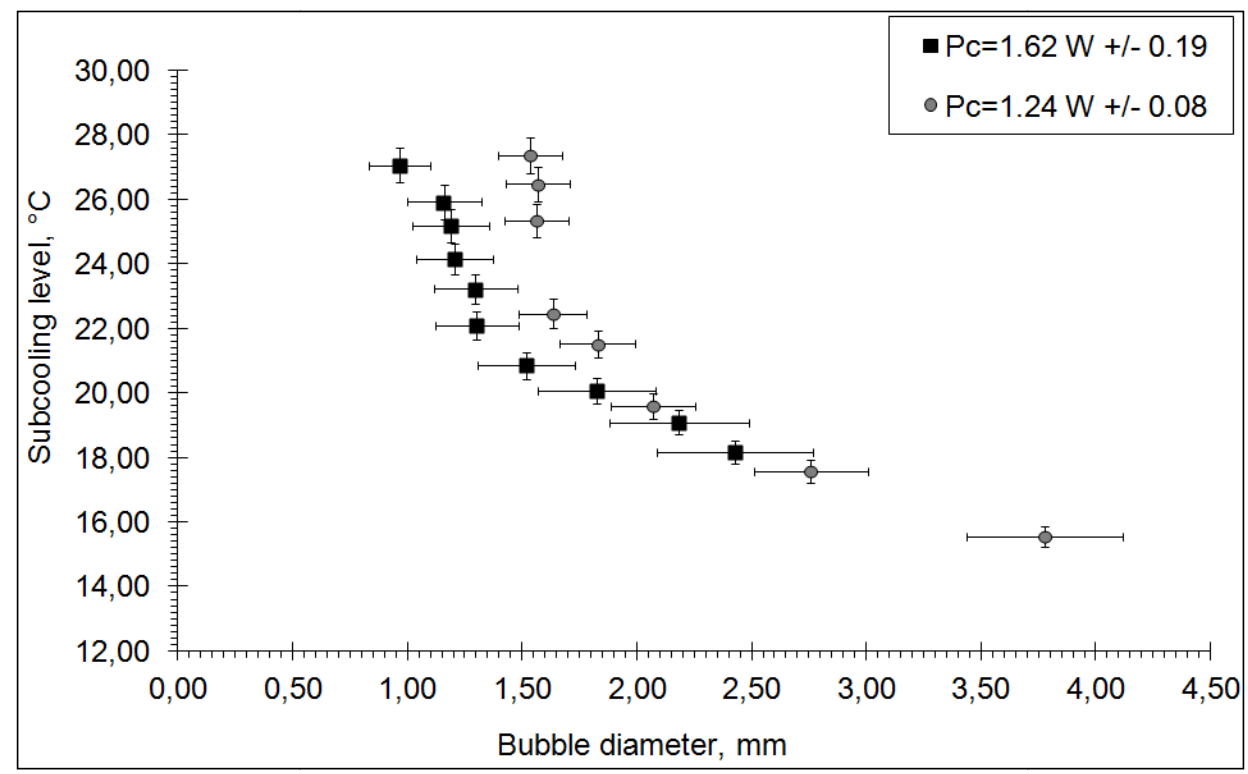

Figure 4. Liquid level of subcooling versus the critical bubble diameter. Threshold from stationary to oscillatory Marangoni modes.

4

American Institute of Aeronautics and Astronautics 
In parallel to shadowgraphy acquisition, we carried out PTV experiments. After the image processing, we obtained velocity vector fields from which we determined that the velocities in the rolls were between 0.1 and 0.2 $\mathrm{mm} / \mathrm{s}$. Those values are consistent with those obtained by Wozniak et al. ${ }^{15}$ who carried out PIV (Particle Image Velocimetry) experiments around an air bubble injected into a silicone oil layer. They found that their maximum velocities in the Marangoni roll were around $0.1 \mathrm{~mm} / \mathrm{s}$.

An example of a velocity vector field obtained by PTV is given on the Fig. 5. A convective roll (in the red rectangle on the image) near the liquid-vapor interface is visible on the left side of the bubble. This flow is related to the Marangoni effect, which appears along the liquid-vapor interface. The direction of rotation of the liquid in the roll is clockwise. Near the liquid-vapor interface, the liquid moves from the hot area (close to the heating element) to the cold area (top of the bubble, in contact with the subcooled liquid). The temperature gradient existing along the vapor bubble interface induces a gradient of surface tension: the liquid moves from the area with low surface tension to the one with a high surface tension. Our test fluid (FC-72) has a surface tension which increases when decreasing the temperature. Consequently the fluid moves from the hot zone to the cold one.

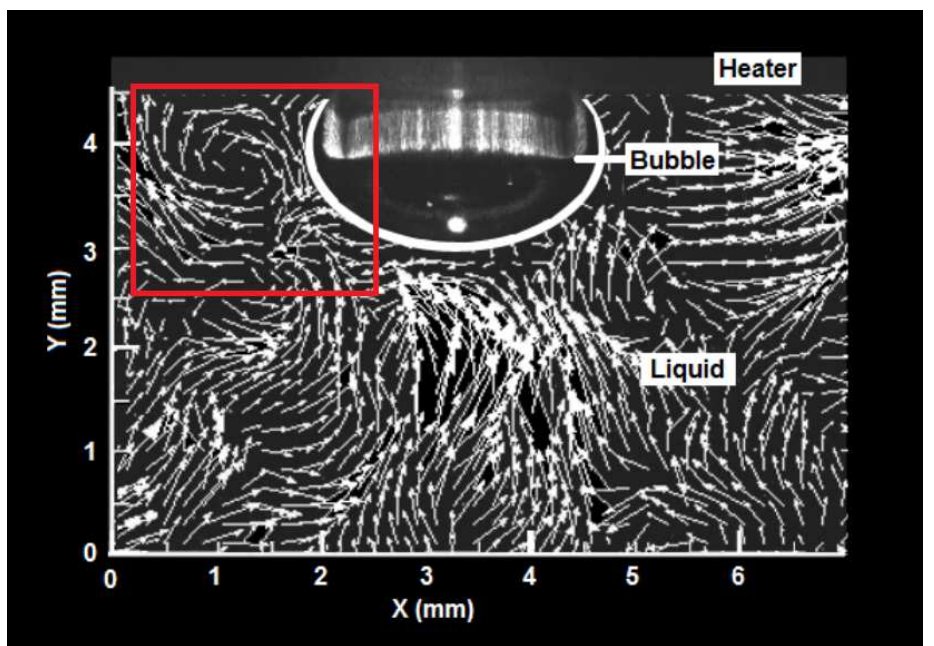

Figure 5. Velocity vector field showing the Marangoni Roll around the vapor bubble. Obtained by PTV, Level of subcooling $=16.9{ }^{\circ} \mathrm{C} \pm 0.2, \mathrm{Pc}=1.62 \mathrm{~W} \pm 0.19$.

On the Fig. 5, only one roll is observed. This can be explained by the fact that, according to results from shadowgraphy, at this bubble size and these thermal parameters, we are in the oscillatory mode (cf. Fig. 4). Or this oscillatory mode is highly $3 \mathrm{D}$ (the deformed torus has a rotation motion in the horizontal plan), the classic PTV method being 2D, we are currently developing and testing a 3D-3C optical method: the RVV (Rainbow Volumetric Velocimetry) ${ }^{15}$. RVV will enable us to obtain the three velocity components along the 3 spatial directions, and thus describes the whole convective motion in the volume of measure around the vapor bubble.

\section{Conclusion}

An experimental setup was designed to study Marangoni convection around a single vapor bubble. Two optical methods were carried out: shadowgraphy and PTV (Particle Tracking Velocimetry). Under normal conditions of gravity and pressure, and for various operating conditions (levels of subcooling and wall heat flux), limits between the stationary and the oscillatory mode were found. Critical diameter increased when either the levels of subcooling or the wall heat flux decreased. Moreover, velocity vector fields were obtained, from which order of magnitude of the maximal velocities in the convective rolls were found to be around $0.1-0.2 \mathrm{~mm} / \mathrm{s}$. Results obtained with phase change were compared with those from the literature (without phase change), and were found to be consistent. The oscillatory mode being highly 3D, our prospects are to carry out a new optical method: the RVV (Rainbow Volumetric Velocimetry). 


\section{Acknowledgments}

The authors very gratefully acknowledge the experimental help of C. Balley-Vidal.

\section{References}

${ }^{1}$ Dihr, V, "Nucleate and transition boiling heat transfer under pool and external flow conditions," International Journal of Heat and Fluid Flow, Vol. 12, 1991, pp. 290, 314.

${ }^{2}$ Scriven, L. E. and Sternling, C. V., “The Marangoni Effects,” Nature, Vol. 187, 1960, pp. 186, 188.

${ }^{3}$ Raake, D., Siekmann, J., and Chun, C., "Temperature and velocity fields due to surface tension driven flow," Experiments in Fluids, Vol. 7, 1989, pp. 164, 172.

${ }^{4}$ Petrovic, S., Robinson, T., and Judd, R. L., "Marangoni heat transfer in subcooled nucleate pool boiling," International Journal of Heat and Mass Transfer, Vol. 47, 2004, pp. 5115, 5128.

${ }^{5}$ Straub, J., "Origin and effect of thermocapillary convection in subcooled boiling," Ann. N.Y. Acad. Sci., Vol. 974, 2002, pp. 348,363 .

${ }^{6}$ Barthès, M., Reynard, C., Santini, R. and Tadrist, L., "Non-condenable gas influence on the Marangoni convection during a single vapour bubble growth in subcooled liquid," Europhysics Letters, Vol. 77, 2007, pp. 14001.

${ }^{7}$ Henry, C., Kim, J., and McQuillen, J., "Dissolved gas effects on thermocapillary convection during boiling in reduced gravity environments," Heat and Mass Tranfert, Vol. 42, 2006, pp. 919, 928.

${ }^{8}$ Reynard, C., Barthès, M., Santini, R. and Tadrist, L., "Experimental study of the onset of the 3D oscillatory thermocapillary convection around a single air or vapor bubble : Influence on heat transfer," Experimental Thermal and Fluid Science, Vol. 29, 2005, pp. 783, 793 .

${ }^{9}$ Chun, C. H., Raake, D. and Hansmann, G., "Oscillating convection modes in the surroundings of an air bubble under a horizontal heated wall," Experiments in Fluids, Vol. 11, 1991, pp. 359, 367.

${ }^{10}$ Rashidnia, N., "Bubble dynamics on a heated surface," Journal of Thermophysics and Heat Transfer," Vol. 11, 1997, pp. 477, 480.

${ }^{11}$ Wozniak, G., "Optical whole-field methods for thermo-convective flow analysis in microgravity," Measurement Science and Technology," Vol. 10, 1999, pp. 878.

${ }^{12}$ Arlabosse, P., Tadrist, L., Tadrist, H. and Pantaloni, J., "Experimental analysis of the heat transfer induced by thermocapillary convection around a bubble," Journal of Heat Transfer, Vol. 122, 2000, pp. 66, 73.

${ }^{13}$ Carvalho, V., Barthès, M., Lepiller, V. and Bailly, Y. "Caracterisation de la convection thermocapillaire autour d'une bulle de vapeur nuclée par la méthode PIV 2D," Congrès Français de Visualisation et de Traitement d'Image en Mécanique des Fluides, FLUVISU, Lille, 2011

${ }^{14}$ Reynard-Carette, C., "Etude expérimentale de la convection thermocapillaire autour d'une bulle par méthodes optiques et thermiques. Influence de la gravité sur les régimes d'écoulement et les transferts de chaleur," Ph.D. Dissertation, IUSTI Université de Provence, 2001.

${ }^{15}$ Wozniak, K., Wozniak, G., Rösgen, T., "Particle-Image-Velocimetry applied to thermocapillary convection,” Experiments in Fluids," Vol. 10, 1990, pp. 12, 16.

${ }^{16}$ Prenel, J.P., Bailly, Y., "Recent evolutions of imagery in fluid mechanics : From standard tomographic visualization to 3D volumic velocimetry," Optics and Lasers in Engineering," Vol. 44, 2006, pp. 321, 334. 